Article

\title{
Development of Digital Competence in Secondary Education Teachers' Training
}

\author{
María Napal Fraile ${ }^{1, *(1)}$, Alicia Peñalva-Vélez ${ }^{2}$ and Ana María Mendióroz Lacambra ${ }^{2}$ \\ 1 Department of Sciences, Universidad Pública de Navarra, Pamplona 31006, Spain \\ 2 Department of Human Sciences and Education, Universidad Pública de Navarra, Pamplona 31006, Spain; \\ alicia.penalva@unavarra.es (A.P.-V.); anamaria.mendioroz@unavarra.es (A.M.M.L.) \\ * Correspondence: maria.napal@unavarra.es; Tel.: +34-948-169-493
}

Received: 13 June 2018; Accepted: 18 July 2018; Published: 20 July 2018

\begin{abstract}
Digital competence is one of the eight key competences for life-long learning developed by the European Commission, and is a requisite for personal fulfilment and development, active citizenship, social inclusion, and employment in a knowledge society. To accompany young learners in the development of competence, and to guarantee optimal implementation of information and communication technologies (ICTs), it is necessary that teachers are, in turn, literate. We had 43 secondary school teachers in initial training to assess their own level of competence in 21 subcompetences in five areas identified by the DIGCOMP project, using the rubrics provided in the Common Digital Competence Framework for Teachers (Spanish Ministry of Education). Overall, pre-service teachers' conceptions about their level of digital competence was low (Initial). Students scored highest in information, which refers mostly to the operations they performed while being students. Secondly, in safety and communication, excluding protection of digital data and preservation of digital identity. Lowest values were achieved in content creation and problem solving, the dimensions most closely related with the inclusion of ICTs to transform teaching-learning processes. The knowledge or skills they exhibit are largely self-taught and, so, we perceive an urgent need to purposefully incorporate relational and didactic aspects of ICT integration.
\end{abstract}

Keywords: Common Digital Competence Framework for Teachers; Digital Competence; Digital Communication; Digital Content Creation; Informational literacy; Problem Solving; Safety; Teacher Training

\section{Introduction}

In late 1997, the Organisation for Economic Co-operation and Development (OECD) launched the DeSeCo Project, with the aim of providing the conceptual basis required to identify key competences, or competences that individuals need to acquire to be prepared for life's challenges [1]. These may include individual demands - employability, personal development-as well as collective challenges - such as balancing economic growth with environmental sustainability, and prosperity with social equity. In these contexts, the competences that individuals need to meet their goals have become more complex, requiring more than the mastery of certain narrowly defined skills.

Very shortly after, the European Commission recognised the importance of life-long learning as a response to ongoing globalization and the shift towards knowledge-based economies, and already, in 2005, urged Member States to adapt their educative systems to provide the young with the key competencies required to engage in life-long learning. Although competences exceed, by far, simple knowledge or skills-competence means the ability to meet complex demands by drawing on and mobilising knowledge, skills, and attitudes in a particular context [1]—competences can and should be taught at school. 
The Recommendation of the European Parliament and of the Council of 18 December 2006 on key competences for lifelong learning [2] was intended to provide a common European reference framework on these key competences for policymakers, education and training providers, social partners, and learners themselves, and support other related policies, such as employment and social policies and other policies affecting youth. The recommendation identified a set of eight competencies that all individuals need for personal fulfilment and development, active citizenship, social inclusion, and employment.

One of these eight competences was digital competence, defined as the creative, critical, and safe use of information and communication technologies (ICT) to reach goals related to work, employability, learning, leisure, inclusion, and social participation. According to the DIGCOMP project-the project on Digital Competence, launched by the European Comission to the better understanding and development of Digital Competence in Europe-[3], digital competence involves not only basic technical mastery, but also the development of abilities to (1) browse, evaluate, and manage information; (2) communicate and collaborate; (3) create digital contents; (4) preserve safety; and (5) solve problems, both in formal, non-formal, and informal learning contexts [4]. The acquisition of this competence also requires attitudes and values that allow the user to adapt to the new needs established by technologies, their appropriation and adaptation to their own purposes, and the ability to interact socially around them. Digital competence allows individuals to take advantage of the wealth of new possibilities associated with digital technologies and the challenges they pose; it is also increasingly necessary to participate meaningfully in the new knowledge society and economy of the 21st century. Media literacy [5] enables the literate person to fully develop as an active and free member of a society surrounded by innumerable media.

With this in view, educational policies have made evident efforts to introduce ICT in schools [6,7], in the belief-or rather, hope-that ICT will improve learning [8] and assure digital literacy. Governments have adopted policies to provide internet access for every child and every school, while the industry has supported diverse digital education initiatives, and families have made efforts to gain internet access at home, acknowledging the pivotal role of digital technologies in the 21st century [8].

However, strong evidence for the alleged benefits of ICTs, and for their impacts on a wide variety of student learning outcomes remain elusive [8,9]. Data supports the claim that the use of technologies in class increases motivation and curiosity for learning and improvement in the use of technologies [10]. Further reviews have shown that integration of ICT not only significantly improves practical knowledge of applications and programmes, but also contributes to developing skills and fosters an active and autonomous role of the student [11]. Nevertheless, there is an increasing awareness among experts that, for potential attainment outcomes to be fully realised, ICT needs to be used to support subject learning and to impact on pupils' subject-specific learning processes [12], and that ICT has only a limited effect on learning and teaching when teachers limit themselves to small enhancements, without appreciating that interactivity requires a new approach to pedagogy and the curriculum [9].

This highlights the need to ensure adequate development of the digital competence of teachers [13]. For teachers, who act as architects of the teaching-learning processes, being digitally literate means being able to properly integrate ICTs as part of the teaching process to transform it [14]. The basis of effective teaching with technology is the understanding that emerges from interactions among content, pedagogy, and technology knowledge (TPACK; [15]), and the evidence shows that when teachers use their knowledge of both the subject and the way students understand the subject, their use of ICT has a more direct effect on the students' attainment [9]. In other words, "Digital competence is the teacher's proficiency in using ICT in a professional context with good pedagogic-didactic judgment and his or her awareness of its implications for learning strategies and the digital bildung of pupils" ([13], p. 252)

Furthermore, the increasing penetration of ICT in our classrooms, and also in quotidian contexts outside of schools, does not guarantee that students develop satisfactorily their digital competence [11] 
beyond technical mastery. In this sense, teachers also have an essential role because of their position as an adult reference for children and adolescents [13].

In fact, the digital literacy training of teachers and families was recognised as part of the education objectives for the decade, 2010-2020, proposed by the Spanish Ministry of Education [16], partly because many adults (parents and teachers) are unable to guide children in the use of proper codes and responsible utilization of ICTs [10]. One of the reasons of this difficulty might be [17] the inversion of the educative system: Whereas, in the first half of the 20th century, it was adults who transmitted the knowledge and the necessary experience map, and now young people have a better knowledge of the new codes [10]. Garrido-Lora et al. [17] call this phenomenon the "generational digital divide", which is revealed by "the existence of evident differences between generations both in knowledge and in the use of ICT and social networks" (p. 52). Teachers could often be considered visitors in the technological world, as they access technologies only when it is necessary, and not routinely and naturally as young people do [18]. Adults (both the family and in the school) must acquire the proficiencies of the new literacy that will allow them to overcome the digital and inter-generational divide [16], as "it is of key importance that everyone-parents and guardians, teachers, institutions, and governments - work together to create safe and accessible environments for children and young people wherever they are: At home, at school, or in public facilities, such as libraries or Internet cafés" ([19], p. 2). In consequence, both schools families face the challenge of contributing to promote the necessary media and digital literacy [16], and to reduce the generational digital divide [17].

Teachers' training programs (both initial and continuous training) have long ignored this demand, but it is now necessary that researchers or institutions assess the real situation of this collective for managers to introduce the measures that are required. Otherwise, if what is needed to achieve change in teachers' behaviour in the classroom is not considered, the efforts invested in training may be largely ineffective [20].

The Spanish Master's Degree in Secondary School Teaching seems an ideal context to carry out this inquiry. According to the Organic Law of Education 2/2006 of 24 May, in Spain, the qualifications required to teach in compulsory and upper secondary education include a Bachelor's degree (or an equivalent qualification) and didactic training, in the form of the Master's degree. In other words, the main objective of this Master's degree is to train students as secondary education teachers, i.e., professionals equipped to teach the subjects pertaining to their discipline, and, accordingly, it has a professional orientation. Students have themselves (at least some of them) been raised in a technology-rich environment, both at the school and outside, and are, in turn, being trained to work in increasingly equipped schools where technological innovation is increasingly valued to work with 12 to 18-years old teenagers, among whom autonomous learning and safety in interpersonal interactions are of paramount importance.

Considering this, the objective of this work is two-fold:

- To identify the Master's Degree in Secondary School Teaching students' conception of their own level of digital competence; and

- to identify priority areas to be addressed in initial teacher training in Spain.

\section{Materials and Methods}

\subsection{Definition of Teacher Digital Competence}

For the purpose of this paper, we will use the definition of teacher digital competence contained in the Common Digital Competence Framework for Teachers [21]. The Framework provides a common reference for teacher digital competence, which may help to define the minimum requirements that teachers should meet to be able to incorporate ICTs in their teaching and, lastly, to promote a methodological change in education. In this sense, it alleviates a perceived need for a stable and renowned core of common skills and associated evaluable indicators [21], which may serve as a reference in certification and training processes. The Common Digital Competence Framework for 
Teachers is the result of the process of joint reflection by the Spanish Ministry of Science \& Education, autonomous communities and experts.

The Common Framework is composed of 21 sub-competences in 5 areas (Table 1). It is based on the competences described in the DIGCOMP project [3] for all citizens, and develops and adapts them to the context of teaching. Areas 1 to 3 are more specific, and are linked to particular actions and tools; and areas 4 and 5 are transversal. All the areas are equally valuable; what makes a good teacher is the interaction of the five [22].

Each of the 21 sub-competences are described in terms of knowledge, skills, and attitudes, and includes examples of applications to teaching and learning (see one example in Table 2a). Although the competences are numbered, the order is not indicative of progression or difficulty. The first competences in each axis are always the one including the most technical aspects. The instrument includes a set of performance indicators at three levels (Initial, Medium, Advanced), specifically focused on teaching, for each of the 21 items (3-6 per area) (see one example in Table 2b). The document is also available in English [23].

Recently a new version (v2) was released, including a more nuanced definition, with 6 levels of performance (A1-C2) instead of 3, and more finely detailed rubrics [24]. It has an associated on-line tool, The Digital Competence Portfolio for Teachers, which allows teachers to assess their own level of digital competence, offers them opportunities for training to improve, and lets them record evidence for teaching, learning, and training experiences, as a part of a personal portfolio of digital competence.

\subsection{Application Context}

The sample was comprised of 44 students of the Biology and Geology speciality of the Master's Degree in Secondary School Teaching of the Public University of Navarra. Average group size was 14 students (range 13-17) This Master's degree consists of 60ECTS distributed in 2 semesters, including general psycho-pedagogic as well as topic-specific didactic training, and an 8-week $(2+6)$ internship period. The study was performed within the context of the subject, "Introduction to Educational Research and Innovation", during 3 academic courses: 2015/16, 2016/17, and 2017/18. In all the 3 courses, the research instrument was applied in the context of a class activity, in the last weeks of the course and prior to the beginning of the internship period, so the students had been delivered most of the content in the training program, but they still had little practical expertise in the classroom.

The class activity is included in the module $(12 \mathrm{~h})$, "ICT-mediated teaching innovative practices". The module considers some generic types of ICT, and their potential impact in education (from small improvements in learning or the students' experience to a true shift of paradigm), and the conditions for a fruitful introduction, which are: (1) A good pedagogical integration, which considers the SAMR—for the initials of Substitution, Augmentation, Modification, Redefinition; the phases of infusion of technologies into teaching and learning [25] and TPACK [15] models; and (2) a digitally competent teacher. The activity serves to introduce and define the actual content of this second and last block.

The activity was introduced during a 45-min long theoretical session. For 10-15 min, the students could discuss, in small groups of $4 / 5$ (round robin), what made a citizen digitally competent. Then, in groups of $8 / 10$, they could compare their lists, and were requested to reformulate them to define the basic common core skills any secondary school teacher should master (10-15 min). For 15 more minutes, they were presented with the 21 sub-competences and 5 areas of the DIGCOMP project [3]; the teacher briefly defined each of them, and allowed students to compare, in their group, their proposals with the model. They were reminded to include their reflections in the personal portfolio. In the last minutes, they were given instructions for completing the proposed task. 
Table 1. General description of the five areas of teacher digital competence, with their 21 sub-competences [3,21].

\begin{tabular}{|c|c|c|c|}
\hline Area & General Description & & Sub-Competences \\
\hline Information and information literacy & $\begin{array}{l}\text { Identify, locate, obtain, store, organize, and analyse digital information, } \\
\text { evaluating its purpose and relevance. }\end{array}$ & $\begin{array}{l}1.1 \\
1.2 \\
1.3\end{array}$ & $\begin{array}{l}\text { Navigation, search, and filtering of information, data, and digital content } \\
\text { Evaluation of information, data and digital content } \\
\text { Storage and retrieval of information, data and digital content }\end{array}$ \\
\hline Communication and collaboration & $\begin{array}{l}\text { Communicate in digital environments, share resources through network tools, } \\
\text { connect with others and collaborate through digital tools, interact and } \\
\text { participate in communities and networks, intercultural awareness. }\end{array}$ & $\begin{array}{l}2.1 \\
2.2 \\
2.3 \\
2.4 \\
2.5 \\
2.6\end{array}$ & $\begin{array}{l}\text { Interaction through digital technologies } \\
\text { Share information and content } \\
\text { Citizen participation online } \\
\text { Collaboration through digital channels } \\
\text { Netiquette } \\
\text { Digital identity management }\end{array}$ \\
\hline Digital content creation & $\begin{array}{l}\text { Create and edit new digital content, integrate and re-elaborate previous } \\
\text { knowledge and content, make artistic productions, multimedia content, } \\
\text { and computer programming, know how to apply intellectual property rights } \\
\text { and licenses for use. }\end{array}$ & $\begin{array}{l}3.1 \\
3.2 \\
3.3 \\
3.4\end{array}$ & $\begin{array}{c}\text { Development of digital content } \\
\text { Integration and reworking of digital content } \\
\text { Copyrights and licenses } \\
\text { Programming }\end{array}$ \\
\hline Safety & $\begin{array}{l}\text { Protection of information and personal data, protection of digital identity, } \\
\text { measures of safety, responsible and safe use. }\end{array}$ & $\begin{array}{l}4.1 \\
4.2 \\
4.3 \\
4.4\end{array}$ & $\begin{array}{l}\text { Protection of devices and digital content } \\
\text { Protection of personal data and digital identity } \\
\text { Protection of health and well-being } \\
\text { Protection of the environment }\end{array}$ \\
\hline Problem-solving & $\begin{array}{l}\text { Identify needs for the use of digital resources, make informed decisions about } \\
\text { the most appropriate digital tools according to the purpose or need, solve } \\
\text { conceptual problems through digital media, use technologies in a creative } \\
\text { way, solve technical problems, update their own competence and of others. }\end{array}$ & $\begin{array}{l}5.1 \\
5.2 \\
5.3 \\
5.4\end{array}$ & $\begin{array}{c}\text { Solving technical problems } \\
\text { Identification of needs and technological answers. } \\
\text { Innovation and use of digital technology in a creative way } \\
\text { Identification of gaps in digital competence }\end{array}$ \\
\hline
\end{tabular}

Table 2. Complete profile of one of the sub-competences, as provided in The Common Digital Competence Framework for Teachers [21]. (a) Name and description, proficiency levels, and application examples for the sub-competence 1.1 (Browsing, searching, and filtering information) (Area of Information). (b) Performance indicators adapted to teachers.

(a)

Dimension 1

Name of are

Dimension 2 Competence title and description
Information

Identify, locate, retrieve, store, organise, and analyse digital information, judging its relevance and purpose for teaching needs.

\subsection{Browsing, searching and filtering information}

To access and search for online information, to articulate information needs, to find relevant information, to select resources effectively, to navigate between online sources, to create personal information strategies.

Dimension 3

Proficiency levels 
Table 2. Cont.

I can do some online searches through search engines. I know that different search

engines can provide different results.
I can browse the internet for information and I can search for information online. I can articulate my information needs and I can select the appropriate information I find.
I can use a wide range of search strategies when searching for

information and browsing on the Internet. I can filter and monitor the information I receive. I kno-w whom to follow in online information sharing places (e.g., micro-blogging).

\begin{tabular}{|c|c|}
\hline \multicolumn{2}{|r|}{ Dimension $4{ }^{1}$ Application examples } \\
\hline Knowledge examples & $\begin{array}{l}\text { Understands how information is generated and distributed in digital media. } \\
\text { Understands which search engines or databases best answer his/her own information needs. }\end{array}$ \\
\hline Skills examples & $\begin{array}{l}\text { Adjusts searches according to specific needs. } \\
\text { Can follow information presented in hyper-linked and non-linear form. }\end{array}$ \\
\hline Attitude examples & $\begin{array}{l}\text { Has a proactive attitude towards looking for information. } \\
\text { Values the positive aspects of technologies for information retrieval. }\end{array}$ \\
\hline \multicolumn{2}{|r|}{ (b) } \\
\hline Level & Descriptor \\
\hline I (Initial) & $\begin{array}{l}\text { 1. Locates information in different formats using keywords on search engines, and makes them suitable for inclusion in the design of } \\
\text { educational activities. }\end{array}$ \\
\hline M (Medium) & $\begin{array}{l}\text { 2. Configures web browsers, finds dynamic information sources of interest to the teaching profession, and manages the monitoring of } \\
\text { these information flows for his/her professional updating. }\end{array}$ \\
\hline A (Advanced) & $\begin{array}{l}\text { 3. Designs a customized search strategy and access to information in different formats that allows the continuous updating of resources, } \\
\text { best practices and educational trends. }\end{array}$ \\
\hline
\end{tabular}

${ }^{1}$ Only two examples provided for illustration. The complete list can be found at [21] 
The task consisted of filling in, individually, a supplied Excel document with their level of competence (Foundation, Medium, Advanced) for each of the 21 sub-competences, according to the rubrics in the Common Digital Competence Framework for Teachers [21], which had been made available to them. The Excel document stored the 21 single values, automatically computed an average value for the area, and plotted the values in a radial diagram with 5 axes (1/area) to enable visual inspection of the results. The students were requested to submit the self-assessment, so that the results of the class could be combined prior to discussion in class. The data were presented the following day, in class, and this served to identify major gaps and to negotiate formative targets for the next sessions. To maximise reliability, the students were given the opportunity to edit the submitted document to correct any unintentional errors or misinterpretations in their self-evaluations (e.g., misunderstanding of any of the sub-competences) and to resubmit them. Only the last version was considered for further analysis.

All the data recorded are available as Supplementary Material (Table S1 Dataset).

\section{Results}

\subsection{Description of the Research Subjects}

43 students in total (13-17 per year) completed the activity. Students had previously completed degrees in Biology, Geology, or Environmental Sciences and, exceptionally, careers related to Health or Engineering. Most students had accessed the Master's immediately or shortly after having finished their degree, although a few of them had professional experience in teaching (mostly informal) or research.

In general terms, the average age was 29.65 years (range 23-50), and they had been in (limited) contact with ICTs in the role of students. The sample was moderately gender-balanced (26 female/17 male).

\subsection{Levels of Teacher Digital Competence}

Overall, future teachers perceived they had a low level of Digital Competence: over $50 \%$ of the respondents placed themselves at a basic level in 14 of the 21 sub-competences, and in only 3 items more than $20 \%$ considered to be at an advanced level.

There were differences among areas (Kruskal-Wallis; $F=25.18 ; d f=4 ; p<0.001$ ): Scores for information were higher than for any of the other areas, among which no significant differences were found (Tukey contrasts; Figure 1).

The Master's students taking part in the survey scored highest in information (search, filtering, evaluation, storage, and retrieval of information, data, and digital content) (see Table 3 and Figure 2).

Safety was the second most valued category: Nearly one fourth of the students (21.2-26.5\%) placed themselves at the advanced level in three of the four sub-competences in the area; namely, protection of devices and digital content (4.1), protection of health and well-being (4.3), and protection of the environment (4.4). It is noteworthy that $53 \%$ of the Master's students declared a basic level (1) on protection of personal data and digital identity (4.2).

As for the area of communication, the students felt prepared (at an intermediate level) to interact and share information and content $(2.1 ; 2.2)$, but their unawareness of codes in digital communication and preservation of digital identity $(2.5 ; 2.6)$ was noteworthy

Likewise, Master's students could identify needs and come up with technical solutions (or seek for specialized help) $(5.1 ; 5.2)$, but failed to innovate with technologies (5.3) and to identify gaps in their own digital competence (5.4).

Last, content creation was the least developed area of competence, with over $60 \%$ of the students placed at a basic level in all of the four indicators, including not only teacher-specific tasks, such as Development of Digital Content (3.1) and Integration of Digital content (3.2), but also the existence and proper use of copyright and licenses (4.3). 


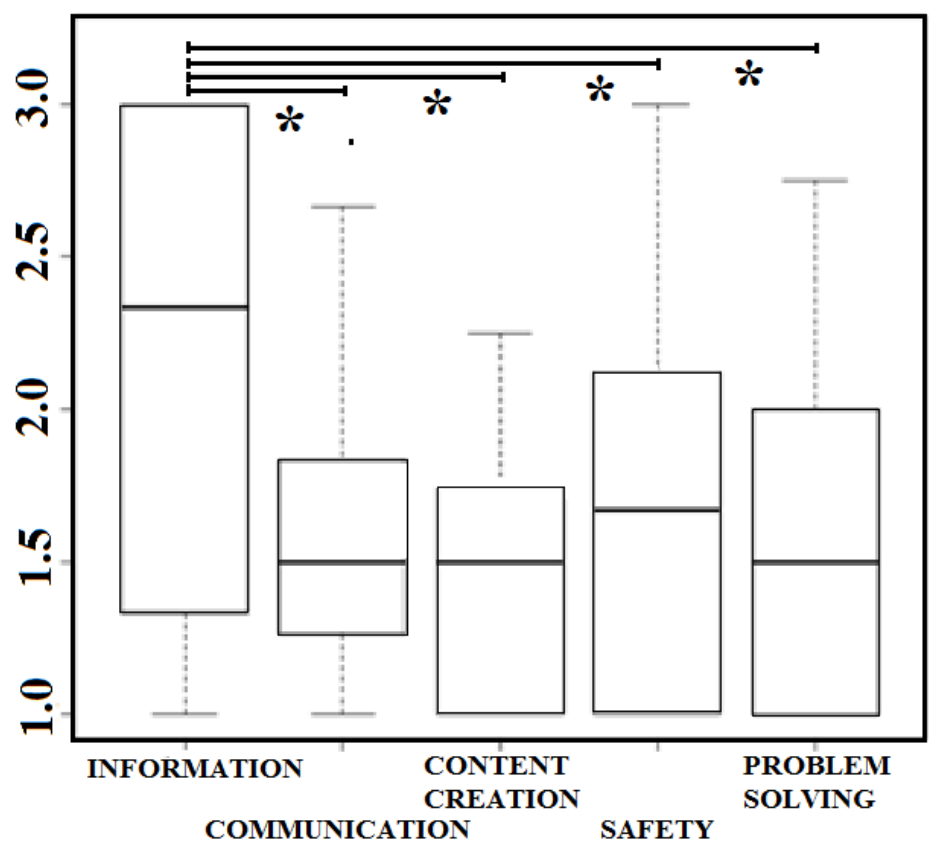

Figure 1. Boxplot depicting mean scores per area of teacher digital competence [21]. The asterisk $\left(^{*}\right)$ indicates significant differences $(p<0.05)$ among areas.

Table 3. Percentage of students at each level of performance for the 21 sub-competences in the five areas of teacher digital competence [21] as described in Table 1.

\begin{tabular}{ccccc}
\hline Area & Item & (1) Initial & (2) Medium & (3) Advanced \\
\hline \multirow{4}{*}{ Information } & 1.1 & 48.6 & 50.0 & 2.9 \\
& 1.2 & 40.0 & 44.1 & 17.6 \\
& 1.3 & 37.1 & 50.0 & 14.7 \\
\hline \multirow{5}{*}{ Communication } & 2.1 & 34.3 & 55.9 & 11.8 \\
& 2.2 & 42.9 & 47.1 & 11.8 \\
& 2.3 & 62.9 & 32.4 & 5.9 \\
& 2.4 & 57.1 & 38.2 & 5.9 \\
& 2.5 & 51.5 & 43.8 & 3.1 \\
& 2.6 & 51.4 & 44.1 & 5.9 \\
\hline \multirow{5}{*}{ Sontent creation } & 3.1 & 57.1 & 41.2 & 2.9 \\
& 3.2 & 71.4 & 29.4 & 0.0 \\
& 3.3 & 67.6 & 21.2 & 12.1 \\
& 3.4 & 70.6 & 27.3 & 0.0 \\
\hline \multirow{5}{*}{ Problem-solving } & 4.1 & 40.0 & 38.2 & 23.5 \\
& 4.2 & 52.9 & 39.4 & 9.1 \\
& 4.3 & 47.1 & 33.3 & 21.2 \\
& 4.4 & 45.7 & 29.4 & 26.5 \\
\hline & 5.1 & 42.9 & 55.9 & 2.9 \\
& 5.3 & 51.4 & 50.0 & 0.0 \\
\hline
\end{tabular}

Most frequent category $(1,2,3)$ is coloured: Red for Initial, orange for Medium. When two categories differ less than $5 \%$, both are shadowed. 


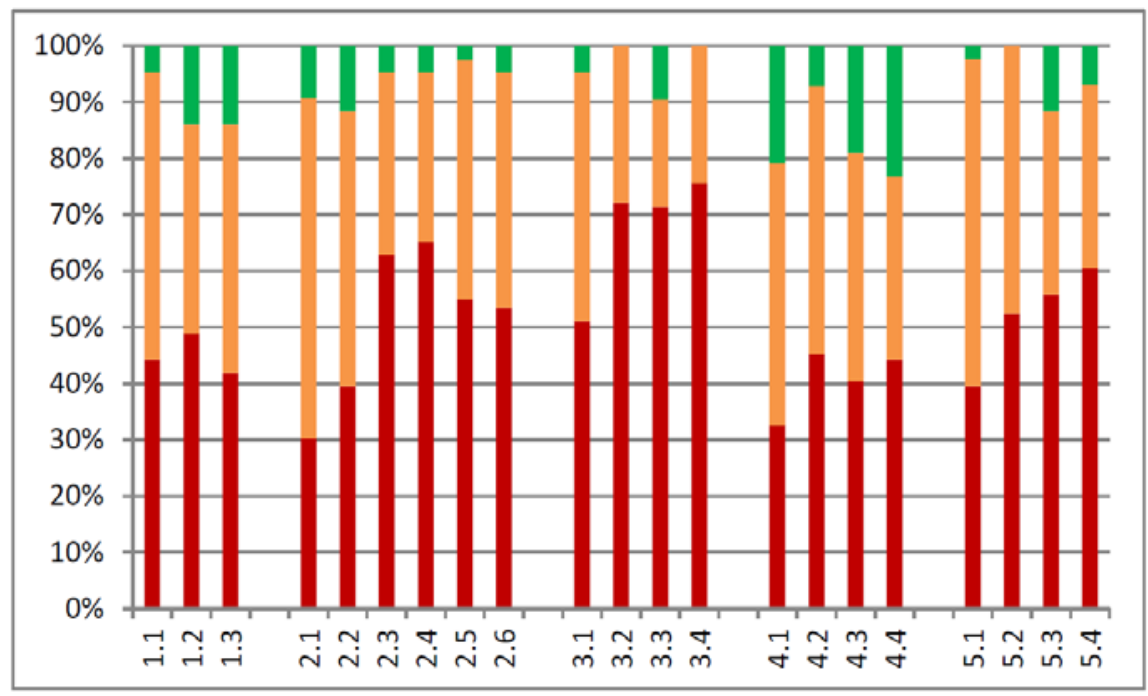

Figure 2. Percentage of students at Initial (red), Medium (orange), and Advanced (green) levels of performance for each of the 21 sub-competences in the five areas of teacher digital competence, as described in Table 1.

\subsection{Among Groups Comparison}

There was no difference in the level of competence with sex, neither globally (Wilcoxon's W $=5322$; $p=0.498$ ) nor when considering separately each area.

However, there was a negative correlation in the level of digital competence with age (rho $=-0.140$; $p=0.012$ ), which was mostly due to differences in content creation decreasing with the age of respondents.

\section{Discussion}

Teachers in initial training (Master's Degree in Secondary School Teaching of the Public University of Navarre have, in general, a poor conception of their own level of digital competence, as defined by the INTEF (National Institute for Educational Technologies and Teacher Training, dependent on the Spanish Ministry of Education, Culture and Sport) in the Common Digital Competence Framework for Teachers [21], which defines and develops the key ideas included in the DIGICOMP project [3]. Although high school students have incorporated ICTs into their daily lives, they are by no means the experts we could imagine, and they are not fully aware either of their potential benefits in education or of the risks of using them badly (as in [26]). These data reveal they are far from acquiring the new competences that are necessary for thriving in digital ecosystems, including: Learning throughout life (life-long learning), making maximum profit from ICTs to adapt and evolve thinking and learn to learn [27], and raising concerns about their ability to incorporate technologies into their routine classes in an adequate and standardized way [28].

In general, they are most competent in the dimensions in which they were trained as students (or, at least, exposed to): Interacting and sharing information (communication), and browsing, storing, and retrieving digital data and contents (information). These could be considered instrumental and intellectual-cognitive skills [29], though, and do not ensure the acquisition of other dimensions of the competencies: For example, even if they know how to use the technologies to mediate interactions, they are unaware of the codes used in digital media (netiquette), the concept of digital identity, or are unable to generate true cooperation online.

Problem solving and content creation, which partly contribute to the sociocomunicational competences described by [29], are the least developed areas, despite being the most closely related with the work of teachers, which they will eventually carry out. We must be aware that the implementation of new ICT-mediated didactic approaches relies on both students and teachers acquiring information, 
media, and communication literacy (i.e., digital competence) [30], which, in view of our results, is not the case for prospective teachers. Innovative teaching with ICT requires much more than the mastery of basic ICT skills [31]. Until student teachers learn to innovate using digital technology in a creative way, ICTs will fail to become LCT (learning and communication technologies); i.e., realize their potential to impact learning and, lastly, transform education.

Although safety is the second-best area, there are still notable difficulties. Already concerning, students most often consider they are at a basic level in protection of personal data and digital identity; and, likewise, in citizen participation, netiquette, and management of their digital profile (area of communication). This belongs to both the axiological and emotional competences [29]. For individuals to be able to interact socially around new technologies and to participate actively in the new knowledge society responsible and respectful use of ICTs is required, and adults (teachers and families) must be accountable for this objective. If they are to serve as a reference for students, it is essential that teachers are acquainted with these concepts, and can apply them to their own interactions, whatever their speciality is.

Overall, although it must be acknowledged that the students taking part in the exercise had not yet finished their initial training, our results suggest that they did not receive enough training or that it was not very effective in promoting their digital competence (see also [32]). Anecdotic data retrieved from informal conversations with students suggests that their actual level of competence has been acquired through informal experiences and self-teaching, but not because of purposeful training in a context, e.g., teachers' training programmes. In fact, Spain was, in 2013, the country offering the most hours per teacher of training in ICT, and, yet, the teachers felt underprepared for integrating technological tools into their teaching [33]. Also, although there is a weak association with age, being young (i.e., supposedly "digital native" (sensu [34])) does not guarantee an adequate level of personal skills development, and less so with the development of professional skills. Becoming literate implies knowing and using technologies, with not only use [5], but also integration of ICTs in teaching might be much more demanding for the teacher than it has usually been considered [20].

Considering this, from our perspective, there is a real need for wisely designed training programs (whether initial training for novice teachers or continuous training), which help to close this divide between the demands posed by a knowledge society and the end-of-course profile of newly formed secondary school teachers. It should include the three big areas comprised in the definition of teachers' digital competence: Technology proficiency, pedagogical compatibility, and social awareness [13]. One of the pillars should be fostering a real integration of pedagogical, technological, and content aspects [15] to help the student teachers learn about how specific ICT resources con enhance and fundamentally change the way in which their students learn [9]. It is unjustifiable that discomfort or lack of confidence in using ICTs prevent today's teachers from embracing new pedagogical approaches [35], but, on the other hand, courses that only focus on technical skills and not on the pedagogical aspects of ICTs are repeatedly reported as being inefficient [35]. The second pillar should include safety, digital identity, and proper use of codes in communication: Notwithstanding the importance of the didactic aspects of ICTs (or their contribution to learning and acquisition of skills), the relational components of digital competence should also be given priority in training initiatives.

In this sense, we found the aforementioned Common Digital Competence Framework for Teachers very useful [24], which may aid in identifying these gaps and designing corrective or compensatory measures; i.e., deciding which areas of knowledge need to be integrated into teacher training curricula and what the goal of this knowledge is. Although other models have been developed (e.g., the renowned [13]), the Spanish Common Digital Competence Framework for Teachers is more comprehensive, also including, explicitly, ethical or relational aspects; it aligns with the DIGCOMP project, the current European reference [3]; and, unlike the recent [22], it provides rubrics and detailed performance indicators that allow for a standardized assessment of competence level.

One possible limitation of the study is the fact that it is based on students' self-assessment, which is known to be a somewhat inaccurate predictor of digital competence among preservice teachers [36]. 
However, our aim is not to provide an unbiased estimation of the true level of digital competence, but to afford a comparison among areas of competence, in the context of an activity of reflection within a training module. Despite its limitations, it is, to the best of our knowledge, the first approach to the level of digital competence of pre-service secondary school teachers using an standardized framework, as most of the previous studies were either focused on primary school and/or devoted to assessing the effectiveness of various methodologies (see [36]).

Although teachers' experiences of what they learnt contributes to improving students' learning outcomes and is essential for the success of training programmes [20,32], and this could be suggestive that we should better direct our efforts to in-service staff who can involve investigation- action cycles in real classrooms, we still believe that initial training programmes should serve to, at least, raise concern among students and provide some basis for further professional development. Further research on the actual level of competence might help to set precise learning goals.

Supplementary Materials: The following are available online at http://www.mdpi.com/2227-7102/8/3/104/s1, Table S1: Secondary School Teaching Master students' self-assessment of Digital Competence.

Author Contributions: All the three authors have contributed equally to this manuscript.

Funding: This research received no external funding.

Acknowledgments: The study was funded by EDU2016-76743-P (MINECO), though funds received were not received to cover the cost of publishing in open access. We would also like to thank the students who participated in the study.

Conflicts of Interest: The authors declare no conflict of interest

\section{References}

1. Organization for Economic Cooperation and Development. The Definition and Selection of Key Competencies: Executive Summary; Organization for Economic Cooperation and Development: Paris, France, 2005.

2. European Council. Recommendation of the European Parliament and the Council of 18 December 2006 on Key Competencies for Lifelong Learning. Bruss. Off. J. Eur. Un. 2006, 30, 2006.

3. Ferrari, A. DIGCOMP: A Framework for Developing and Understanding Digital Competence in Europe; Publications Office of the European Union: Luxembourg, 2013; Volume EUR 26035.

4. Spanish Government. Orden ECD/65/2015, de 21 de Enero, Por la Que se Describen las Relaciones entre las Competencias, los Contenidos y los Criterios de Evaluación de la Educación Primaria, la Educación Secundaria Obligatoria y el Bachillerato. Bol. Of. Estado 2015, 25, 6986-7003.

5. Buckingham, D. Más Allá de la Tecnología. Aprendizaje Infan-Til en la era de la Cltuura Digital; Manantial: Buenos Aires, Argentina, 2008.

6. Ramos, M.C.A.; Olivencia, J.J.L. La participación de las familias en las escuelas TIC: Análisis y reflexiones educativas. Píxel-Bit Rev. Medios Educ. 2012, 40, 7-19.

7. Area, M.; Sanabria, A.L.; Vega, A.M. Las políticas educativas TIC (Escuela 2.0) en las Comunidades Autónomas de España desde la visión del profesorado. Campus Virtuales 2013, 2, 74-88.

8. Livingstone, S. Critical reflections on the benefits of ICT in education. Oxf. Rev. Educ. 2012, 38, 9-24. [CrossRef]

9. Cox, M.J.; Marshall, G. Effects of ICT: Do we know what we should know? Educ. Inf. Technol. 2007, 12, 59-70. [CrossRef]

10. Plaza, J.; Caro, C. La implicación de la familia en la formación ético-cívica de los jóvenes a través de las TIC. Aloma 2016, 34, 97-106.

11. Saez López, J.M. Valoración del impacto que tienen las TIC en educación primaria en los procesos de aprendizaje y en los resultados a través de una triangulación de datos. Campus Virtuales 2012, 11, 11-24.

12. Passey, D.; Rogers, C.; Machell, J.; McHugh, G.; Allaway, D. The Motivational Effect of ICT on Pupils; Department of Educational Research: Lancaster, UK, 2004.

13. Krumsvik, R.J. Situated learning and teachers' digital competence. Educ. Inf. Technol. 2008, 13, 279-290. [CrossRef] 
14. Passey, D. Technology enhancing learning: Analysing uses of information and communication technologies by primary and secondary school pupils with learning frameworks. Curric. J. 2006, 17, 139-166. [CrossRef]

15. Koehler, M.J.; Mishra, P. What is Technological Pedagogical Content Knowledge? Contemp. Issues Technol. Teach. Educ. 2009, 9, 60-70. [CrossRef]

16. Aguilar, M.C.; Contreras, R.A.U. La necesidad de alfabetización digital e inter-generacional en la familia y la escuela. Didáct. Innov. Multimed. 2014, 28, 1-16.

17. Garrido-Lora, M.; Duran, J.B.; Ramos, R.À.M. From ICT to ICRT. A study of ICT use and the digital divide among adults and adolescents in Spain. Anàlisi 2016, 54, 44-57. [CrossRef]

18. Mayorgas, M.J. Programas de prevención de la adicción a las nuevas tecnologías en jóvenes y adolescentes. In Adicción a las Nuevas Tecnologías en Adolescentes y Jóvenes; Echaburúa, E., Labrador, F.J., Begoña, E., Eds.; Pirámide: Madrid, Spain, 2009; pp. 221-225.

19. Internet Society. Internet and the Children; Internet Society: Reston, VA, USA, 2012.

20. Wikan, G.; Mølster, T. Training Teachers to Use ICT as an Integrated Part of Their Teaching. Eur. J. Teach. Educ. 2011, 34, 209-218. [CrossRef]

21. INTEF. Proyecto "Marco Común de Competencia Digital Docente" del Plan de Cultura Digital en la Escuela; INTEF: Madrid, Spain, 2013.

22. Kelentriç, M.; Helland, K.; Rstorp, A.-T. Professional Digital Competence Framework for Teachers; The Norwegian Centre for ICT in Education: Tromsø, Norway, 2017.

23. INTEF. Marco común de Competencia Digital Docente. Available online: http:/ / educalab.es/documents / 10180/12809/Marco+competencia+digital+docente+2017/afb07987-1ad6-4b2d-bdc8-58e9faeeccea (accessed on 08 June 2018).

24. Puentedura, R. Transformation, technology, and education. Retrieved Febr. 2006, 18, 504-520.

25. Aguaded, J.I.; Guerra, S. Razones para una educación mediática en la sociedad multipantanas. Sphera Pública 2012, 12, 21-39.

26. Trilling, B.; Fadel, C. 21st Century Skills: Learning for Life in Our Times; John Wiley \& Sons: San Francisco, CA, USA, 2009.

27. López Mondéjar, L.M.; Sánchez Marín, F.J.; González López, A. Alfabetización mediática y educación en TIC en la universidad. In Humanizar la Utilización de las Tic en Educación; Fernández Delgado, A., Gutiérrez Rivas, P., Tabasso, E., Eds.; Dykinson: Madrid, Spain, 2016; pp. 23-26.

28. Area-Moreira, M.; Ribeiro-Pessoa, M.T. From Solid to Liquid: New Literacies to the Cultural Changes of Web 2.0. Comunicar 2012, 19, 13-20. [CrossRef]

29. Gisbert, M.; Esteve, F. Digital learners: La competencia digital de los estudiantes universitarios. La Cuest. Univ. 2011, 7, 48-59.

30. Røkenes, F.M.; Krumsvik, R.J. Prepared to teach ESL with ICT? A study of digital competence in Norwegian teacher education. Comput. Educ. 2016, 97, 1-20. [CrossRef]

31. Guskey, T.R. Professional development and teacher change. Teach. Teach. 2002, 8, 381-391. [CrossRef]

32. European Commission. Survey of Schools: ICT in Education. Benchmarking Access, Use and Attitudes to Technology in Europe's Schools; European Commission: Brussels, Belgium, 2013; p. 163.

33. Prensky, M. Digital natives, digital immigrants. Horizon 2001, 9, 1-6.

34. Balanskat, A.; Blamire, R.; Kefala, S. The ICT Impact Report: A Review of Studies of ICT Impact on Schools in Europe; European Schoolnet: Brussels, Belgium, 2006; p. 75.

35. Maderick, J.A.; Zhang, S.; Hartley, K.; Marchand, G. Preservice Teachers and Self-Assessing Digital Competence. J. Educ. Comput. Res. 2015, 54, 326-351. [CrossRef]

36. Røkenes, F.M.; Krumsvik, R.J. Development of Student Teachers' Digital Competence in Teacher EducationA Literature Review. Nord. J. Digit. Lit. 2014, 4, 250-280.

(C) 2018 by the authors. Licensee MDPI, Basel, Switzerland. This article is an open access article distributed under the terms and conditions of the Creative Commons Attribution (CC BY) license (http:/ / creativecommons.org/licenses/by/4.0/). 